\title{
African female university students' experiences of online education at home during the COVID-19 pandemic
}

\section{Ansurie Pillay}

School of Education, University of KwaZulu-Natal, Durban, South Africa Pillaya3@ukzn.ac.za

https://orcid.org/0000-0002-9174-0543

\section{Martha Khosa}

School of Education, University of KwaZulu-Natal, Durban, South Africa KhosaM1@ukzn.ac.za

https://orcid.org/0000-0002-7294-2182

\section{Bridget Campbell}

School of Education, University of KwaZulu-Natal, Durban, South Africa Campbell@ukzn.ac.za

https://orcid.org/0000-0003-4305-3391

\section{Nicholus Nyika}

School of Education, University of KwaZulu-Natal, Durban, South Africa NyikaN@ukzn.ac.za

https://orcid.org/0000-0003-1464-9444

\section{Ayub Sheik}

School of Education, University of KwaZulu-Natal, Durban, South Africa Sheika@ukzn.ac.za https://orcid.org/0000-0002-8633-3740

(Received: 24 February 2021; accepted: 13 August 2021)

\section{Abstract}

The purpose of the study on which this paper is based was to explore how self-identified female African university students understand the influence of their home environments on their experiences of online education. The study took place during the COVID-19 pandemic when universities in South Africa and elsewhere introduced online teaching and learning. Using a qualitative approach to a single case study design within a critical feminist paradigm, we carried out an inductive thematic analysis of the data from seven indepth, open-ended questionnaires and metaphors. We found that home environments play an important role in 
the education of female African students, particularly in a context characterised by gender inequalities exacerbated by inequities in material resources. However, a sense of agency, displayed by some participants, indicated their determination to rise above the many forms of marginalisation and discrimination they experienced.

Keywords: gender inequalities, online teaching and learning, material inequities, home environments, COVID19 pandemic

\section{Introduction}

On 23 March 2020, South Africa went into a national lockdown in an attempt to reduce the spread of the novel coronavirus that was sweeping the globe. University students living in oncampus residences in South Africa were forced to return to their homes to commence online teaching and learning. Students in South Africa come from diverse social and economic backgrounds as Mdepa and Tshiwula (2012) have reminded us, and large numbers of them hail from overcrowded, poverty-stricken homes in areas characterised by social ills such as hunger, crime, and violence (Bhorat et al., 2017).

For many female African students, leaving campus residences and returning home meant taking on a number of traditional and cultural gender-based responsibilities, including household chores and caring for family members as Awung and Dorasamy (2015) have noted. This study, conducted well before the start of the COVID-19 pandemic, found that many more household activities are assigned to females than to males and this serves as an enormous obstacle to academic progress. A 2020 study by Fura and Negash showed that the pandemic exacerbated the existing marginalisation of female students, who constitute a vulnerable group in society globally and locally, affected their psychological health, and decreased their motivation to pursue their studies.

In this study, we focus on self-identified female African university students since they constitute the majority student population with whom we work at our university. Universities in South Africa require that students self-identify their race and gender, among other demographics, and we drew on such information when sampling participants. The female African participants were studying towards a Postgraduate Certificate in Education (PGCE) in a School of Education at a higher education institution in KwaZulu-Natal, South Africa. We used the following research question to guide the study: How do female African university students understand the influence of their home environments on their experiences of online education in the context of a pandemic? Our study, located within a critical paradigm, employed a qualitative approach within a single case study design. Mama's (2004) theory of African feminism that challenges the subordination of women, underpinned the study.

In this paper, we discuss our use of African feminism as a theoretical framework, review the relevant literature on the topic, outline the methodology we used, discuss the findings, and provide concluding thoughts. 


\section{Theoretical framework}

We found African feminism as a theoretical framework to be most compatible with an analysis of female African university students' experiences of online education at home during the COVID-19 pandemic. African feminism derives from a rich array of political, cultural, and ideological histories and is "informed by the many diverse and creative ways in which African women contest power in their private and public lives" (Ahikire, 2014, p. 8). It is particularly focussed on identifying the traditionally established ways along with new ones in which women in Africa defeat oppression (Arndt, 2002). As Salo and Mama (2001, p. 60) have noted, "African feminism evolves a politics that challenges the status quo implicit in the way contemporary patriarchies in Africa constrain women and prevent them from realising their potential beyond their traditional roles as industrious income-generating wives and mothers." Lewis (2001) further noted that, in the interests of efficiency, women are burdened with increasing their productivity to uphold both patriarchy and capitalism.

On the African continent, many women experience conditions of economic marginalisation and extreme poverty (Techane, 2017). They enact gender roles in the context of other oppressions such as racism, socio-economic exclusion, and cultural imperialism (Arndt, 2002). Over the years, feminist scholarship has explored the varied nature of women's experiences across the African continent as well as their marginalisation in the development agendas of their countries (Mama \& Barnes, 2007). Similarly, there has been a realisation that African women's experiences of marginalisation and patriarchy differ from those experienced by women in the West (Lewis, 2001) and differ across the continent, giving rise to calls for differentiated agendas and interventionist activism (Nnaemeka, 1998; Steady, 1987; Wane, 2011).

In higher education, although a notable change has been observed with the attainment of a gender balance of undergraduate students, concerns have been raised about the lack of gender equality given the existence of what David (2015, p. 10) has called "patriarchy or hegemonic masculinity." In this study we recognise that with students being forced to leave campus during the pandemic, higher education learning has moved into their homes. We explore how female African students understand the influence of their home environment on their experiences of online education. We do this by reading and sharing their stories that function to subvert male-dominated canons, pre-existing histories, and assumptions of gender. The need to give students a voice is set against Amaefula's (2021) recognition that African women's stories need to be understood against an historic background of male privilege that has led to gender inequality. As lecturers and researchers working in this theoretical paradigm, we recognise Nkealah's (2006) contention that to understand students' stories requires modulating our own subjectivity, manifest in our multiple positionings as political, institutional, ethicised, gendered, sexualised, and classed subjects from particular locations. 


\section{Literature review}

In the ongoing COVID-19 pandemic with its subsequent physical distancing measures, many students, irrespective of gender, are uncertain of their academic futures because of campus closures, isolation, and the pivot to online learning (Hellemans et al., 2020). Mandatory physical distancing measures and restrictions on social gatherings have left many students feeling disconnected from their campuses where support and services are typically available (Dumas et al., 2020). As coping mechanisms, some students have resorted to increased use of substances such as alcohol and cannabis (Dumas et al., 2020).

In a study that focused on the psychological health of university students during the COVID19 pandemic, Fura and Negash (2020) noted that hopelessness, fear, anxiety, worthlessness, emotional detachment, powerlessness, loss, depression, isolation, and loneliness were prevalent among students. Similarly, a study by Tasso et al. in 2021 reported that, with the pandemic, students were adversely affected by a sudden disruption in their daily routines, experienced isolation, and anxiety, and were worried that those close to them would contract the virus. The psychosocial effects of the pandemic must also be understood in conjunction with the multiple stressors unique to this developmental period of students (Beiter et al., 2015). The unique challenges that students are facing during the pandemic could lead to a decline in academic performance and higher attrition rates (Hellemans et al., 2020).

While physical distancing and isolation lead to their own challenges, the turn to online teaching and learning gives rise to further demands. Hofmeyr (2020) stated that material conditions decide students' learning experiences and Czerniewicz et al. (2020) have contended that the implementation of remote online teaching and learning in South Africa has revealed inadequacies previously invisible since many of the students reside in university residences and thus have access to required academic services and support. Challenges related to inadequate resources are compounded by additional responsibilities at home that are not conducive to learning.

Turning the focus specifically to female African students, Bissoonauth (2020) cites Ouedraogo, who in an African Union webinar entitled, "Addressing the impacts of the COVID-19 pandemic on girls' and women's education", cautioned that with closed schools and university campuses, African females are at greater risk of abuse, sexual violence, trafficking, social exclusion, and forced labour. Additionally, Bissoonauth (2020) posited that many female students have had to return to the agricultural fields to help their families, have become unpaid domestic workers, and have been exposed to transactional sex. In addition, the health crisis has forced many female students to drop out of schools and universities and enter the labour market or acquiesce to early marriage.

Young women are also at increased risk of loneliness, depression, and anxiety, especially as COVID-19 fatigue sets in (Hellemans et al., 2020). As Bissoonauth (2020) noted, the COVID-19 related death of men has meant that many women have become the main incomeearners in their households. Additionally, women have become primary caregivers for sick 
family members and for younger siblings. As Plan International (2020) has found in relation to past epidemics, resources are diverted from routine health services, and this has further exacerbated the plight of women.

\section{Methodology}

Following DeCarlo (2018), we located this qualitative single case study within a critical paradigm that is concerned with societal inequities. Simons (2009) maintained that a "case study can document multiple cases" so we used this approach to document the seven participants' experiences explored in the study. Case studies are also "useful for exploring and understanding the process and dynamics of change" (p. 14) and this spoke to our research intention to explore participants' experiences in a context of the pandemic. In addition, case study design seeks to gain "an intensive, holistic description and analysis of a single phenomenon" (Stake, 1995, p. 27) that, in this study, was female African university students' experiences of online education at home during the COVID-19 pandemic.

Using a critical paradigm implies that the research study questions the status quo and focuses on the dynamics of power within a society, including the interaction of race, class, gender, education, and socio-economic factors, among others (Kincheloe \& McLaren, 1994), so we sought to explore female African students' experiences of online education at home during the COVID-19 pandemic. We considered the power dynamics in their homes and explored how gender, specifically, played a role in the learning process.

The seven participating PGCE students were studying to become English Home Language teachers. Besides self-identifying as African and female, they also self-identified as single and their ages ranged from 21 to 28 . We drew the seven participants from two campuses where this qualification is offered. We decided to use convenience sampling which allows for choosing participants who are attainable (Cohen et al., 2011) since one of us in the research team had taught these students and thus had access to them. All potential participants were invited via WhatsApp to participate, and we worked with the seven participants who were willing to become involved.

A limitation was recognised early since the invitation went out at the conclusion of the module when students did not necessarily have access to data and/or network connectivity, and some had moved to places where they would start new jobs. The pandemic dictated that we could not physically meet with the participants and being interviewed online was problematic for some students. It was thus decided to send out open-ended questionnaires.

Once all ethical procedures were in place, the questionnaires were emailed to the participating students who were reminded that participation was voluntary, reassured that their anonymity and that of the university was assured, that their input would be kept confidential, and that withdrawal from the study without penalty was an option.

Of the seven participants, four lived in under-resourced rural areas and did not have reliable access to the internet nor funds to purchase data, two lived in peri-urban communities, and 
one was situated in the greater urban area of Durban. The last-mentioned participant was the only self-funded one. Four participants were classified as what is known as a missing-middle student, whom Samuel (2020) identified as students who are too poor to pay for university but not poor enough to warrant government funding. The remaining two students had government funding.

The participants could respond to the open-ended questionnaires in their own time without any of us being present and this increased the likelihood of objective and honest responses as Ganga and Maphalala (2018) have observed. The open-ended questions meant that participants were free to include as much information in their own words as they wanted to offer (see McLeod, 2014).

In addition to open-ended questionnaires, we asked the seven participants to each include a metaphor that expanded on what they expressed in their questionnaires. Asking for these metaphors enabled the generation of creative data so that the phenomenon under study (students' experiences of online learning at home) could be explored from a unique and alternative perspective (Carpenter, 2008). In line with Carpenter's suggestion, metaphors were used to clarify participants' words, and served to express their feelings and sentiments about online learning in their home environments during a pandemic. In addition to asking the participants to offer a metaphor to comment on the phenomenon under study, we asked them to explain their metaphors and this, too, served as data.

Once data from the questionnaires and metaphors was generated, we started an inductive thematic analysis. We generated the themes from the data rather than fitting the data into preexisting codes and themes (see Braun \& Clarke, 2006). We analysed the data in phases, as suggested by these scholars. In the first phase, we worked independently with the data by reading and familiarising ourselves with it, and in the second phase, each of us independently generated preliminary codes. Still working independently in the third phase, we all searched for themes in relation to data extracts. In the fourth phase, we each chose specific themes of relevance to the study and research question, found extracts from the data to support such themes, and identified the links to the research question. In phase five, we independently named and defined our chosen themes. These independent analysis phases afforded each of us the opportunity to become familiar with the data so as to "trigger deeper reflection on the data's meaning" (Kalpokaite \& Radivojevic, 2019, p. 47). In the sixth phase, we met, motivated for the themes we had individually identified, and, as a group, made our thematic choices, identified important extracts to use as evidence, and reached consensus about the theory and literature.

We ensured investigator triangulation that involves many researchers in an empirical study (see Denzin \& Lincoln, 2005), through the individual and collaborative discussions of our coding and our agreement on the final themes. We aimed to enable trustworthiness by providing "a[s] rich [a] description of the context and research process" (Samaras, 2011, p. 221), as was possible, as well as through the inclusion of verbatim responses from the questionnaires, metaphors, and metaphor explanations. A limitation of the study was the 
relatively small sample, but a large number of questionnaire-prompts and the use of two data methods generated rich data from which we drew our findings.

\section{Findings}

In responding to the research question about how female African university students understand the influence of their home environments on their experiences of online education in the context of a pandemic, the following four themes were identified: inequities in material resources; inequities in gender roles; the role of the family; and agency. The participants are indicated as Participant 1, 2, 3, 4, 5, 6, and 7 and data is presented from participants' questionnaire responses, their choices of metaphor, and their explanations thereof.

\section{Inequities in material resources}

The participants indicated varying access to material resources including access to networks, electricity, and data. This was confirmed by Participants1, 2, and 7 when they indicated "constant network issues" (Participant 1), "bad network" (Participant 2), and said that "poor network coverage made it very difficult to attend Zoom classes" (Participant 7). As the lockdown, brought on by the pandemic, resulted in remote online teaching, the availability of network coverage determined students' experiences of online education. Thus, participants with poor network coverage "ended up not attending classes" (Participant 2), "submitted work late due to the poor internet connection" (Participant 7), and "could not get emails on time" (Participant 2). Three participants (1, 2, and 7) highlighted how poor material resources in their homes excluded them from participating in the Zoom contact sessions and resulted in a negative teaching and learning experience.

Participants 1 and 4 lived and studied in homes with regular electricity outages which compromised the learning experience. As Participant 1 explained,

I live in a rural area. Electricity is supplied by the municipality, not Eskom [the national electricity supplier]. We have constant power issues. We usually live without electricity for three days. This has a negative impact on my work because my laptop is old and only functions when connected to electricity.

Similarly, Participant 4 noted "regular electricity outages" caused by "regular cable theft in the area." If, as Participant 1 noted, she could not work for three days at a time, she experienced anxiety about being marginalised and excluded from the teaching and learning process and felt that this diminished her future prospects in the educational endeavour. Her possessing only an old laptop also reflects the realities of the inequities in students' material resources. The two participants needed to engage with online education via resources that were not fit for the purpose (old laptops) or not available (electricity). Kehler (2001) pointed out that a critical indicator of a person's standard of living and poverty level is access to basic services such as electricity, together with water and sanitation. Participants 1 and 4 were expected to succeed academically without access to these basic services. 
Other participants (3 and 6) pointed to data, provided by the university, "running out" because of the need to engage with many modules online. Other material disadvantages included lack equipment or "poor learning equipment" (Participants 1 and 4), student funding being "revoked" and not having funds to "buy stationery" or "travel to public libraries or internet cafes" (Participant 4) that could support online learning. The metaphors from Participants1, 6, and 7 also corroborate their challenges. Participant 1 noted that "online learning is as hard as a gravel road", Participant 6 said that "online learning is a gigantic sore, a constant pain", and Participant 7 commented that "online learning is hard as a rock", and explained, "My metaphor shows so many difficulties and hardness I encountered in my online learning experience." Participant 6 likened her experiences of online learning to a medical symptom that causes discomfort and pain. However, she was clear that the symptom is huge and recurrent, thus pointing to her extremely negative experience of online learning. Similarly, Participant 1 reflected that the difficulties that were encountered were like a rutted road that is not smooth and that leads to a bumpy ride while Participant 7 reflected on just how arduous the online learning experience has been.

The findings above point to participants working in contexts of lack over which they have no control. They recognise the frustrations and anxieties that they face given the lack of material resources available to them. These findings above resonate with those of Abrams and Szefler (2020) who noted that approximately 5.5 million South Africans live in areas without electricity and internet connectivity and that only $10.4 \%$ of South Africans have internet connectivity at home. Similarly, Czerniewicz et al. (2020) found that many South African university students either lack or have inadequate devices and connectivity to engage in remote online learning. When we look at these findings from the perspective of African feminism, it becomes clear that the participants cited above are marginalised and socioeconomically excluded. Such exclusion places them at risk academically (see Arndt, 2002), through no fault of their own.

While some participants experienced many challenges because of not having material resources, other participants' experiences were different. While Participants 3 and 6 noted having intermittent problems with online learning, Participant 3 said that her online "experiences were good", and Participant 6 said that the "network in my area is good", despite her metaphor indicating that "online learning is a gigantic sore, a constant pain." Both participants were able to complete work, engage with learning, and had generally positive experiences of online education, despite some challenges. It becomes clear that having material resources on the site in which learning happens enables more effective educational experiences and being without such resources seriously hampers educational progress. These findings resonate with those of Hofmeyr (2020) who found that the material conditions within which students find themselves determine their learning experiences.

\section{Inequities in gender roles}

Kehler (2001) indicated that gender involves social and cultural roles and beliefs, attitudes, and expectations, including those relating to the interactions between women and men. The distinct gender roles, and their acceptance of them, is reflected in Participant 3's assertion 
that household chores are gender-based and "that's how our household prefers things to be done. The women balance everything very well." She and her household have internalised a mode of existence, underpinned by patriarchy and cultural expectations, and reinforced by the women in the house, that appears to "work for them." Participant 3's statements betray a false rationality and ideological assumption that exploitative gender relations are normative and should be accepted without question. From an African feminist perspective, we can see that she and the women in her household have imbibed the idea that in the interests of the efficiency of the household, women need to increase their productivity as Lewis (2001) has pointed out. While branches of African feminism speak of complementarity with men (Arndt, 2002), Participant 3 and the women of her home do not want to contest legacies of male dominance and choose to uphold patriarchy.

Participant 1 lives with her mother and noted that "we work together to fulfil home responsibilities, including those that are usually perceived as male duties such as yard cleaning and painting." She pointed out that her home responsibilities cannot be described as being gender-based since the two women in the home manage chores collaboratively.

All seven female participants reflected the entrenched gender roles and six of them highlighted the gender role inequities present in their homes. Participant 2 said, "All cooking and cleaning is done by me." Participant 5 explained, "As a female I am expected to handle all the house chores, like cooking, cleaning and looking after younger siblings", and Participant 7 said, "I do not know how it came about but my brothers do not help with the house chores." The comments of Participants 2, 5, and 7 reflect the entrenched, and now accepted and expected ways of being and acting. They recognise the ways in which gendered roles have been carved into various practices but did not identify how to challenge such assigned roles and chores. Such chores were allocated to them despite the expectations and requirements of the learning process. Participant 6 noted that "house chores are only done by females, and I do them before I start with my studies", and Participant 7 reflected that "as a girl I have to do all the work around the house and that makes me lose time to do my studies." Participants 6 and 7 identified how being solely responsible for house chores, despite having brothers who could help, impacted negatively on their studies. Even in homes where there was an expectation of brothers getting involved, they are "able to run away from chores more easily than I would ever be able to," said Participant 4 . The experiences of Participants 6 and 7 highlight an important focus of African feminism that challenges the supposition that women need to question and change their gendered experiences when in fact, the importance lies with men's examination of masculinity (Lewis, 2001). Participant 4 summed up the sentiments of most of the participants when she said, "Black women are expected to be super women and multi-task even when we are genuinely unable to. Your parents will ask you why you haven't washed the dishes, yet there are other children who don't have studying to do." These findings echo Kolawole's (2002) assertion that the struggles women face in Africa and around the world reside in entrenched male privilege and exploitative gender expectations. 


\section{The role of the family}

When online education becomes based at home during a pandemic, the role of family and friends proves important to the learning endeavour. On a positive note, Participant 3 explained, "My parents understood that they needed to give me some time with my studies." Participant 6 said, "I have an understanding family who accepted that at certain times I would not be available to do anything in the home", and Participant 1 said that her mother "was willing to compromise and do more home responsibilities if [she] had too much university work." Such familial support was recognised by Participants 3 and 6 as a positive contributor to successful online education.

On a negative note, Participant 6 noted "missing Zoom lectures" and added, "I have to look after my grandmother and babysit cousins while I have studies to do." This finding reinforces those of Stats SA (2020) that African women conduct 2,5 times more unpaid care work than do men in South Africa. This, however, is not peculiar to South Africa and is similar in most countries around the world (May \& Hamdulay, 2019). Participant 5 said, "It was difficult convincing my elders that the time spent on my device was really university work and not me trying to escape chores." She reflected on having her mother "calling [her] to do something during a Zoom class." Both participants reflected on the tensions between the university's expectations that they attend and engage with remote online lectures and the family's expectations of support.

Participants also recognised the need to provide support to families in a pandemic. Participant 4 expressed her concern for her cousin who is a nurse and "the stress she is under at work." She also expressed anxiety for "elderly family who face the risk of infection from grandchildren who go out and come home with the disease." Participant 4 pointed to the problem of grandchildren who might not be socially distancing and following other pandemic protocols. While understanding such a concern, Ramparsad (2020) noted that social distancing might not be achievable in many rural and township areas anyway because of the logistics and realities within which people live and work. Participant 1 pointed to family members who "battle with a chronic disease and the anxiety of being infected by COVID19." Such anxieties about vulnerable members of the family must play a role when students are working with the imperative to engage with their remote online education. It also calls to mind a branch of African feminism that locates women in cooperation with, and in affirmation of, family (Arndt, 2002). However, the concerns and anxieties of Participants 1 and 4 call to mind the findings by Hellemans et al. (2020) that the COVID-19 pandemic has resulted in increased levels of anxiety and stress in Canadian female university students.

Participant 5 unpacked a further aspect of how a person's age, gender, and status in the family determines how one acts and how this impacts on learning. She noted,

There is an ongoing availability necessary in an African home. If my father calls me to run an errand (often an hour) whilst I am studying, I will have to leave my room to go to him. I can't say I am studying because, for him, the fact that I am able to leave 
my room means I have time. Not going and calling from the room is disrespectful. Shouting from a room and shouting at an elder-that's a no no in any context.

Here she comments, however implicitly, on the tacit rules regulating behaviour in the acquiescence to the imperative to be available and drop everything should a male elder require something. The educational engagement will need to wait since the educational endeavour is seen to be less important. It is clear that the need to be respectful to a male elder takes precedence over engagement with education. Participant 4's explanation is that "fathers don't understand online learning, so they don't know when and how they are disturbing you. They see you sitting on your phone and don't realise you might be doing something serious." Overall, the combination of elders' ignorance of what these women are doing and the tacit rules in a home make for a difficult learning experience. The sentiments expressed are reflected in Ogunyemi's (1985) findings that an African woman's experiences have to be located within an understanding of her culture and within the various forms of domination and subjugation with which she lives. It appears as if little has changed in the last 35 years.

Participant 4, perhaps, captures the experiences of online learning given the complexities surrounding family and home. Her metaphor is "I am an anchor." She explains,

I am pulled down by my own weight while I try to keep my family steady, to prevent my family from drifting. I am sinking and pulled down by the weight on my shoulders. The academics, financial strains and overthinking pull me down as an anchor would, trying to keep the ship steady, avoiding winds that may drift it away. I am pulled underwater. I hope I do not drown.

Her words reflect her desperation as she balances the burdens of academic requirements, family obligations, and financial concerns, and her sentiments echo the findings of Tasso et al. (2021) that female students are faced with a multitude of challenges of managing and balancing domestic duties and academic imperatives.

\section{Agency}

However, along with the many difficulties of online learning in the home context, the participants reflected a sense of agency and, from an African feminist perspective, found various means to challenge power, or the lack of it, in their personal and public lives (see Ahikire, 2014). When Participant 1 had problems with her laptop, she chose not to despair but "travelled to town" to do her work at the city library. She also chose to "listen to the recordings of the lectures as many times as needed" to facilitate her understanding. She found that the "flexibility of location and time improved [her] understanding and [her] digital literacy." Participant 6 ensured that her lecturers were informed if she was "falling behind." Participant 2 worked with "recorded lectures" when she could not attend Zoom classes and "checked for information on the class WhatsApp group." She said, "I need to study and work at my own pace and at times suitable for me." 
Three participants had worked out a schedule for themselves to enable their completion of all tasks. Participant 1 shared a "daily schedule" involving studies, home chores, exercise, family time, television, and meals. She chose to use her "early mornings" for her studies. She also found that exercising and eating healthily had helped to "ease ... anxiety and depression." She was able to identify ways of overcoming challenges to her psychological health despite conditions of marginalisation, in contrast to the findings of Fura and Negash (2020) and Helleman et al. (2020) that students' psychological health suffered because of the pandemic. Participants 2 and 4 chose to engage in home chores during the day and in their studies at night. The latter said, "I made sure to stay up at night when everyone was asleep as I couldn't concentrate or do much during the day when everyone was awake." Participant 4's response to studying online at home is reflected in the tenet of African feminism that recognises the need for women's affirmation of their families (Arndt, 2002). While not on a schedule, Participant 5 noted that she would do her chores "as quickly as possible, have a break, and start studying." While such home environments and domestic arrangements were not optimal for online learning, the participants cited realised the need to find solutions for themselves.

Three participants drew strength and determination from other women. Participant 1 recounted that her mother encouraged her to "always put education first because, like me, she believes that education is power." Despite her depiction in her metaphor of online learning from home during COVID-19 being like "a car on a gravel road experiencing difficulties", she was determined to keep powering forward. Her metaphor reflects her setbacks and the hurdles she had to overcome, but she does not claim that her car has stalled. Like her, Participant 6 gained her power from a female relative. She drew on her aunt's example and saw an advantage to having her aunt "doing her Masters." She noted that it helped that her aunt "was going through the same thing" as she was. Likewise, Participant 4 was inspired by her cousin, a nurse, who had "the strength to wake up every day and go to work." As she said, "It takes a lot of resilience." Participants I, 4, and 6 drew power from females whom they admired. In line with an African feminist perspective, they found their connectedness to real-life examples and were influenced by their role-models' historical experiences (see Lewis, 2001). Participant 5 learned about herself during this time and identified her metaphor of online learning from home during the pandemic as a "rollercoaster [that] was nervewracking." She added that "the support was overwhelming and much-needed" and noted, "I did the best I could. I did learn a lot about myself and how I deal with new circumstances." Participant 6's metaphor reflects the anxiety and fear related to online learning, but, equally, she recognises the care and assistance she received from others. While the study by Helleman et al. (2020) found that female university students in Canada suffered the effects of social isolation, Participant 6 had the opportunity to turn to others for support and care. Participant $1,4,5$, and 6 realised that they have the option to be strong, intelligent, African women and, as future teachers, it is hoped that they, too, will serve as role models for future generations of African women (see Orakwue, 2018).

Participant 2 presented her metaphor of online learning as a "mountain climb experience with rusty nails along the way" that, despite her burden of carrying her studies, chores, and family, 
all of which "demanded her attention" she was not hindered from continuing to negotiate that terrain. She has a sense of agency and is determined to succeed.

All the female African participants cited above have recognised the challenges and oppressions facing them and have identified ways to overcome them (see Arndt, 2002).

\section{Concluding thoughts}

This study, with its seven female African university students engaging with online education in a pandemic, found that material inequities in students' homes shaped the education each student experienced. Those with material means could continue with their online education and those that did not have these, could not. Material inequities worked together with gender inequities to entrench patriarchal expectations and privileges. If families bought into such expectations and privileges, learning, whether online or not, proved challenging. However, supportive family structures provided the safety for some of these participants to carry on with their education. Despite challenges, whether from material lack, patriarchy, or entrenched family expectations, some participants were able to effect agency in their decisions to do (and be) better.

As can be seen, the experiences of the seven female African students, gleaned through their stories in the open-ended questionnaires and through their metaphors, were appraised from the perspective of African feminism. Many burdens promoted by patriarchy fell to the participants, but they appeared to understand the various identities and roles ascribed to them. They inhabited lives shaped by historical, social, and cultural marginalisation, and many challenged male dominance to varying degrees. Those who chose to flex their agency demonstrated their determination to overcome the oppressions imposed on them.

This study illustrates that while most participants faced marginalisation and discrimination in various forms in their homes, and while some felt particularly vulnerable at many times during the pandemic, most of them emerged as strong resilient African women in simultaneously negotiating the demands of home and tradition on the one hand and education on the other. They chose to redefine their roles and futures in specific and different contexts and traditions. Ultimately, the African female students' experience of studying at home via remote online methods during the COVID-19 pandemic must be recognised for its complexities that could lead to success or failure. Planning for teaching and learning in higher education, whether online or otherwise, needs to acknowledge female African students' realities and provide opportunities for the higher education community to learn about and critique the socially imposed gender (and other) roles that affect in fundamental ways how they live and study

\section{References}

Abrams, E. M., \& Szefler, S. J. (2020). COVID-19 and the impact of social determinants of health. The Lancet. Respiratory Medicine, 8(7), 659-661. 
Ahikire, J. (2014). African feminism in context: Reflections on the legitimation battles, victories and reversals. Feminist Africa, 19, 7-3. vc.bridgew.edu/jiws/vol3/iss1/3

Amaefula, R. C. (2021). African feminisms: Paradigms, problems and prospects. Feminismo/s, 37, 289-305. https://doi.org/10.14198/ fem.2021.37.12

Arndt, S. (2002). Perspectives on African feminism: Defining and classifying Africanfeminist literatures. Agenda: Empowering Women for Gender Equity, 54, 31-44.

Awung, M., \& Dorasamy, N. 2015. The impact of domestic chores on the career progression of women in higher education: The case of the Durban University of Technology. Environmental Economics, 6(4), 94-102.

Beiter, R., Nash, R., McCrady, M., Rhoades, D., Linscomb, M., Clarahan, M., \& Sammut, S. (2015). The prevalence and correlates of depression, anxiety, and stress in a sample of college students. Journal of A $\square$ ective Disorders, 173, 90-96. https://doi.org:10.1016/j.jad.2014. 10.054

Bhorat, H., Lilenstein, A., Monnakgotla, J., Thornton, A, \& van der Zee, K. (2017). The socio-economic determinants of crime in South Africa: An empirical assessment. Working Paper 201704. World Bank Group, University of Cape Town.

Bissoonauth, R. (2020, July 10). Addressing the impacts of the COVID-19 pandemic on girls and women's Education [Webinar]. African Union.

Braun, V., \& Clarke, V. (2006). Using thematic analysis in psychology. Qualitative Research in Psychology, 3(2), 77-101.

Carpenter, J. (2008). Metaphors in qualitative research: Shedding light or casting shadows? Research in Nursing and Health, 31(3), 274-282.

Cohen, L., Manion, L., \& Morrison, K. (2011). Research methods in education (7th ed.). Routledge.

Czerniewicz, L., Agherdien, N., Badenhorst, J., Belluigi, D., Chambers, T., Chili, M., de Villiers, M., Felix, A., Gachago, D., Gokhale, C., Ivala, E., Kramm, N., Madiba, M., Mistri, G., Mgqwashu, E., Prinsloo, P., Pallitt, N., Solomon, K., Strydom, S., \& Swanepoel, M. (2020) A wake-up call: Equity, inequality and Covid-19 emergency remote teaching and learning. Postdigital Science and Education, 2, 946-967.

David, M. (2015). Women and gender equality in higher education. Education Sciences, 5, 10-25. https://doi.org:10.3390/edusci5010010

DeCarlo, T. (2018). Paradigms, theories and how they shape a researcher's approach. https://scientificinquiryinsocialwork.pressbooks.com/chapter/6-2-paradigms-theoriesand-how-they-shape-a-researchers-approach/ 
Denzin, N. K., \& Lincoln, Y. S. (2005). The Sage handbook of qualitative research (3rd ed.). Sage.

Dumas, T. M., Ellis, W., \& Litt, D. M. (2020). What does adolescent substance use look like during the COVID-19 Pandemic? Examining changes in frequency, social contexts, and pandemic-related predictors. The Journal of Adolescent Health: Official Publication of the Society for Adolescent Medicine, 67(3), 354-361. https://doi.org/10.1016/j.jadohealth.2020.06.018

Fura D. L., \& Negash, S. D. (2020). A study on the living experiences of people during the COVID-19 pandemic: The case of Wolisso town home-stayed university students. Journal of Psychology \& Psychotherapy, 10(5), 1-11.

Ganga, E., \& Maphalala, M. (2018). The questionnaire approach. In C. Okeke \& M. van Wyk (Eds.), Educational research - An African approach (pp. 316 -334). Oxford University Press.

Hellemans, K., Abizaid, A., Gabrys, R., McQuaid, R., \& Patterson, Z. (2020, November 24). For university students, COVID-19 stress creates perfect conditions for mental health crises. The Conversation. https://theconversation.com/for-university-studentscovid-19-stress-creates-perfect-conditions-for-mental-health-crises-149127

Hofmeyr, H. (2020). Home background and schooling outcomes in South Africa: Insights from the national income dynamics study. Stellenbosch Economic Working Papers. https://ideas.repec.org/p/sza/wpaper/wpapers294.html

Kalpokaite, N., \& Radivojevic, I. (2019). Demystifying qualitative data analysis for novice qualitative researchers. The Qualitative Report, 24(13), 44-57. nsuworks.nova.edu/tqr/vol24/ iss13/5

Kehler, J. (2001). Women and poverty: The South African experience. Journal of International Women's Studies, 3(1), 41-53.

Kincheloe, J. L., \& McLaren, P. L. (1994). Rethinking critical theory and qualitative research. In N. K. Denzin \& Y. S. Lincoln (Eds.), Handbook of qualitative research (pp.138-157). Sage.

Kolawole, M. M. (2002). Transcending incongruities: Rethinking feminism and the dynamics of identity on Africa. Agenda: Empowering Women for Gender Equity, 54, 92-98.

Lewis, D. (2001). African feminisms. Introduction. Agenda: Empowering Women for Gender Equity, 50, 4-10.

Mama, A. (2004). Demythologising gender in development: Feminist studies in African contexts. IDS Bulletin, 35(4), 121-124. 
Mama, A., \& Barnes, T. (2007). Feminist Africa 8: Rethinking universities. African Gender Institute.

May, C., \& Hamdulay, A. (2019, May 1) MayDay: The burden of unpaid care work on women. IOL News. https://www.iol.co.za/news/opinion/mayday-the-burden-ofunpaid-care-workon-women-22209106

McLeod, S. A. (2014). Questionnaires. www.simplepsychology.org/q

Mdepa, W., \& Tshiwula, L. (2012). Student diversity in South African higher education. Widening Participation and Lifelong Learning, 13, 19-33.

Nkealah, N. (2006). Conceptualizing feminism(s) in Africa: The challenges facing African women writers and critics. English Academy Review, 23(1), 133-141.

Nnaemeka, O. (1998). "Introduction: Reading the rainbow." In O. Nnaemeka, (Ed.), Sisterhood, feminisms, and power: From Africa to the diaspora (pp. 1-35). Africa World Press.

Ogunyemi, C. O. (1985). Womanism: The dynamics of the contemporary black female novel in English. Signs, 11(1), 63-80. https://doi.org:10.1086/494200

Orakwue, A. (2018, March 19). What is African feminism? Urban Woman Magazine. https://urbanwomanmag.com/what-is-african-feminism/

Plan International. (2020, June 25). COVID-19: Lockdown linked to high number of unintended teen pregnancies in Kenya. https://plan-international.org/news/2020-0625-covid-19-lockdown-linked-high-number-unintended-teen-pregnancies-kenya

Ramparsad, N. (2020). Why is COVID-19 different to other pandemics? Assessing the gendered impact of COVID-19 on poor black women in South Africa. Africa Journal of Public Sector Development and Governance, 3(1), 132-143.

Salo, E., \& Mama, A. (2001). Talking about feminism in Africa. Agenda: Empowering Women for Gender Equity, 50, 58-63. http://www.jstor.org/stable/4066405

Samaras, A. (2011). Self-study teacher research: Improving your practice through collaborative inquiry. Sage.

Simons, S. (2009). Case study research in practice. Sage.

Stake, R. E. (1995). The art of case study research. Sage.

Tasso, A. F., Hisli Sahin, N., \& San Roman, G. J. (2021). COVID-19 disruption on college students: Academic and socio-emotional implications. Psychological Trauma: Theory, Research, Practice, and Policy, 13(1), 9-15. http://dx.doi.org/10.1037/tra0000996 
Techane, M. G. (2017). Economic equality and female marginalisation in the SDGs era: Reflections on economic rights of women in Africa. Peace Human Rights Governance, 1(3): 1-33

Wane, N. (2011). African indigenous feminist thought. In N. Wane, A. Kempf \& M. Simmons (Eds.), The politics of cultural knowledge (pp. 7-21). https:/doi.org:10.1007/978-94-6091-481-2_2 